\title{
HAS ITS POTENTIAL BEEN FULLY EXPLOITED?
}

Dear Reader,

has the $\mathrm{CO}_{2}$ reduction potential of the combustion engine been fully exploited? If you ask the experts, none of them seem to be able to give a conclusive answer. The reason for this is simple. The lowhanging fruits of $\mathrm{CO}_{2}$ reduction have already been picked and manufacturers are now looking at a new range of measures which are more complex to implement and, unfortunately, have a much less dramatic effect. And in all the discussions about $\mathrm{CO}_{2}$, we must not forget engine characteristics such as performance and driving dynamics. This makes it all the more essential to coordinate the different systems within the engine, both old and new, more effectively with one another.

One area in which all the systems interact is the gas exchange process. Variable valve timing, cylinder cut-off, downsizing and turbocharging are just some of the factors that influence the gas exchange cycle and, therefore, need to be optimised in order to ensure that the combustion process is as efficient as possible at every engine operating point and that the losses from the gas exchange system are low.

If you would like to find out about the latest trends in the field of gas exchange, I recommend the $7^{\text {th }}$ MTZ conference on "Gas exchange in the combustion engine" which will be taking place on 21 and 22 October 2014 in Stuttgart. The conference covers all the components in and on the engine which help to optimise the mix- ture formation and combustion processes and to reduce the losses during the gas exchange cycle. These include the inlet manifold, turbocharging system, valves and valve train, cylinder head, pistons, exhaust system and engine block. The conference also focuses on the interaction and cooperation of these components. Because the latest developments in relation to the Miller and Atkinson cycles are currently being widely discussed, we have included a larger number of presentations on the basic principles and applications of this technology in the programme. Have I whetted your appetite? You can satisfy it by attending the MTZ conference in Stuttgart.

Best regards,

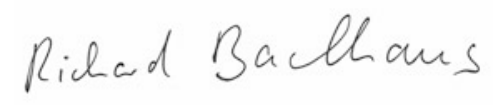

RICHARD BACKHAUS,

Vice-Editor in Chief

Wiesbaden, 8 September 2014

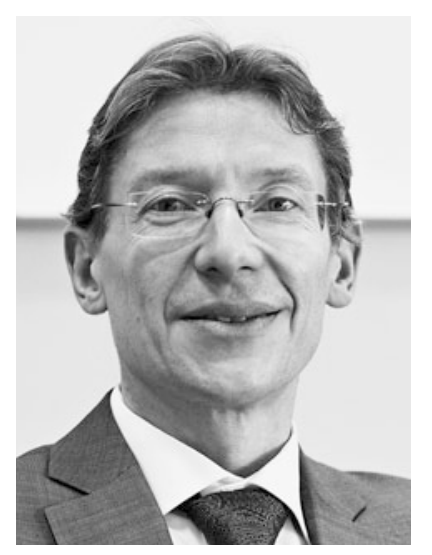

